International Journal of Engineering \& Technology, $9(2)(2020) 424-428$
International Journal of Engineering \& Technology
SPC
Website: www.sciencepubco.com/index.php/IJET
Research paper

\title{
MLR institute of technology campus energy monitoring and controlling system with interconnection of grid and solar power
}

\author{
M. Sreenivasa reddy ${ }^{1 *}$, A. Shubhangi Rao ${ }^{2}$, Ch. Sai Prakash ${ }^{3}$ \\ ${ }^{1}$ Assoc. Professor Department of Electrical and Electronics Engineering, MLR Institute of Technology, Hyderabad \\ ${ }^{2}$ Asst. Professor Department of Electrical and Electronics Engineering, MLR Institute of Technology, Hyderabad \\ ${ }^{3}$ Student Department of Electrical and Electronics Engineering, MLR Institute of Technology, Hyderabad \\ *Corresponding author E-mail: msreddy9848816520@ gmail.com
}

\begin{abstract}
This paper mainly deals with energy consumption and monitoring of each block after carefully observing where the losses occur and how to minimize these losses and how to reduce unit consumption of each block and units consumed by capacitor bank. Base loads and Peak loads can be observed and operated in such a way as to reduce unit consumption.

MLR college has $315 \mathrm{KVA}$ power from the grid as well as $260 \mathrm{KW}$ solar power generating unit where 40 percent of the power from the grid is saved. Proper planning for operating the underground bore motors used for Hostels, Mess and College buildings also saves some amount of units consumed by these motors. Further if power factor is maintained 0.99 instead of 0.2 or 0.3 some amount of units consumed can be saved. Further if maximum demand is prevented from reaching beyond the transformer rating then some amount of units consumed can be saved. Installing copper earth pits of suitable numbers for each block and balancing the loads in each phase can also reduce the losses.

Synchronizing panel is to be connected to the existing 4 generators of rating 200KVA,180KVA and two numbers of $125 \mathrm{KVA}$ to utilize the power resources properly.

The common electrical problems like short circuit, open circuit, over voltage, low voltage, frequent power cuts, low power factor, high electricity bills damage in the meters etc. The above electrical problems are identified, rectified and frequently monitored through modern technologies like IOT.
\end{abstract}

Keywords: Energy Management; Load Duration Curve; Maximum Demand; Power Factor; Reduce Voltage Drops: Current Unbalancing; Day Pricing.

\section{Introduction}

Fault location including types, causes and rectification methods. Calculation of voltages, currents, powers, power factor using tri vector meter and compare theoretically and practically without any losses. Block wise load calculation for all electrical components in $\mathrm{KW}$ or KVA.

To replace older methods by new methods like digital meters in place of analog meters. To improve power factor, power quality and to know power usage block wise or units consumed. To laydown correct rating of transformer for suitable load along with its power cables, distribution panel boards depending upon the load connected. load calculation based on types of loads connected and number of capacitors bank required in KVAR including tri vector meter and other programmable meters. Depend upon the load connected on distribution system in $\mathrm{kw}$ or mw.

Correct size of the transformer to be installed, Power factor improvement, Total connected load of the buildings, Total power consumed in KW, KVAR and power factor, Layout of correct size of the cables, To minimize the faults at distribution system, Power generation using renewable energy sources like solar power, To reduce the wastage of power by adapting IOT based power control.

\section{Load data monitoring}

Our college has $315 \mathrm{KVA}$ transformer one number.200KVA generator one number. 180kva generator one number.125 KVA generators 2 numbers and $260 \mathrm{KW}$ or $33 * 8=264 \mathrm{KVA}$ solar power. Hence the total power capacity including both solar and grid power includes 575 $\mathrm{kw}$ which can supply a maximum of 650 amperes of current. 125kva generator one number is connected to indoor and outdoor stadium.200kva generator is connected to entire college. $180 \mathrm{KVA}$ is connected to mg block.125 KVA one number is connected to new mess and hostel buildings. Power from grid and solar is connected to main incoming where $194 \mathrm{KVA}$ is also connected to it with 1000 amperes change over switch. From mg block with 400amps change over switch 180kva generator is connected then distributed in parallel to VS block, mt block, indoor stadium, mg block, girl's hostel. From VS block it is then connected in parallel to AK block, SR block, JC 
block and CNC lab. Out of $260 \mathrm{kw}$ of solar power. $66 \mathrm{kw}$ of solar power is connected to vs block and the remaining $194 \mathrm{kw}$ is connected to main incoming.

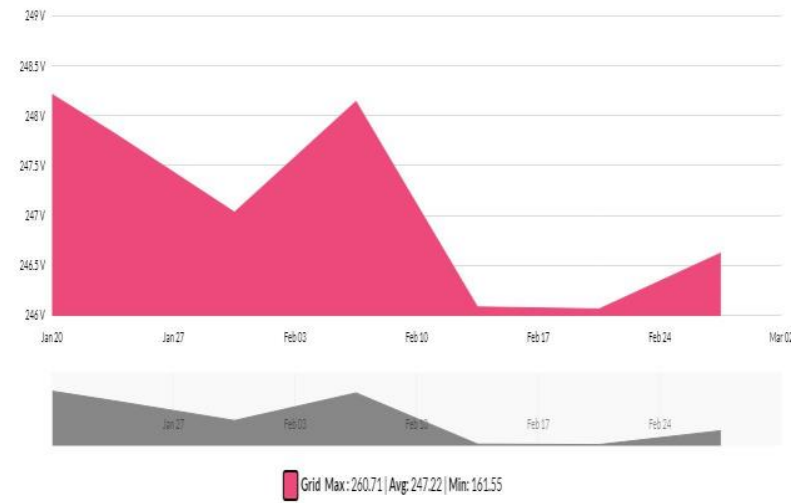

Fig. 1: Voltage Curve of the College per Day.

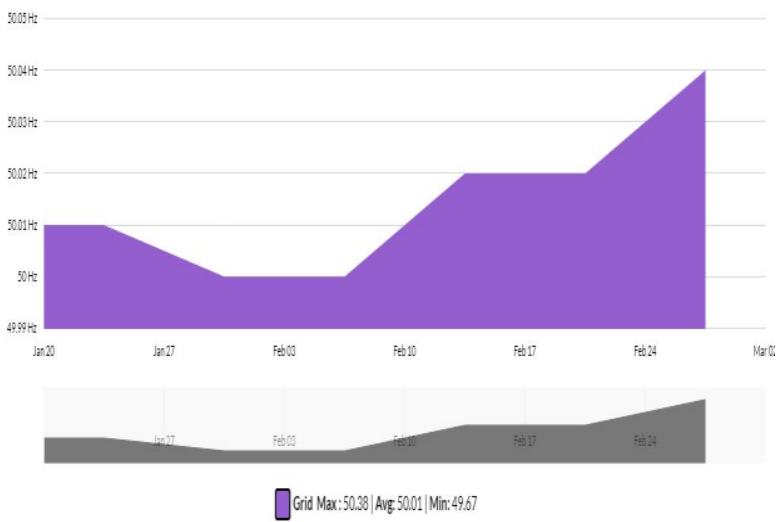

Fig. 2: Frequency Curve of the College per Day.
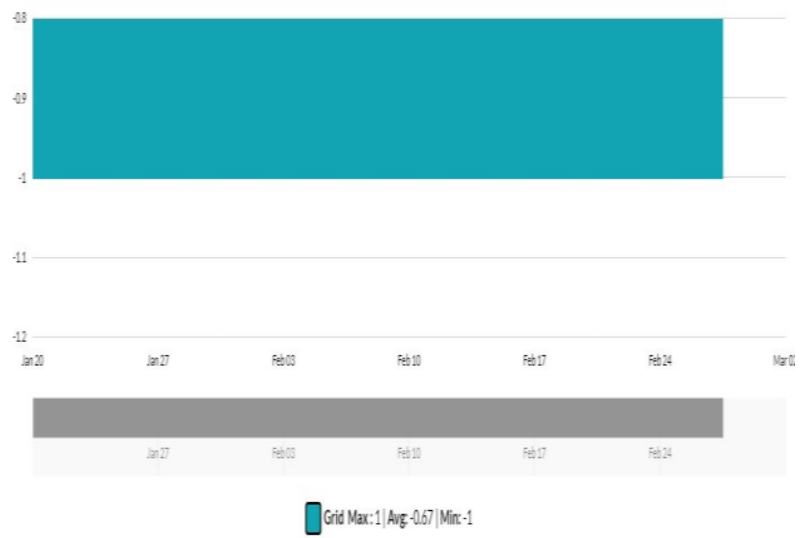

Fig. 3: Power Factor of the College per Day.

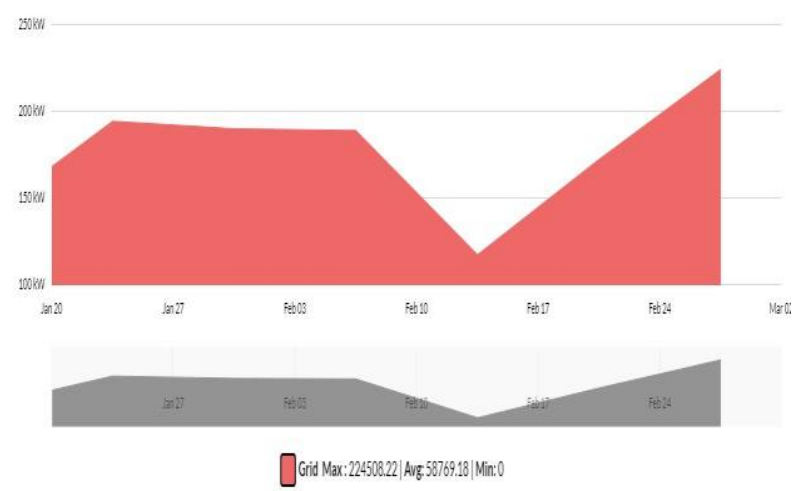

Fig. 4: Maximum Demand of the College per Day. 


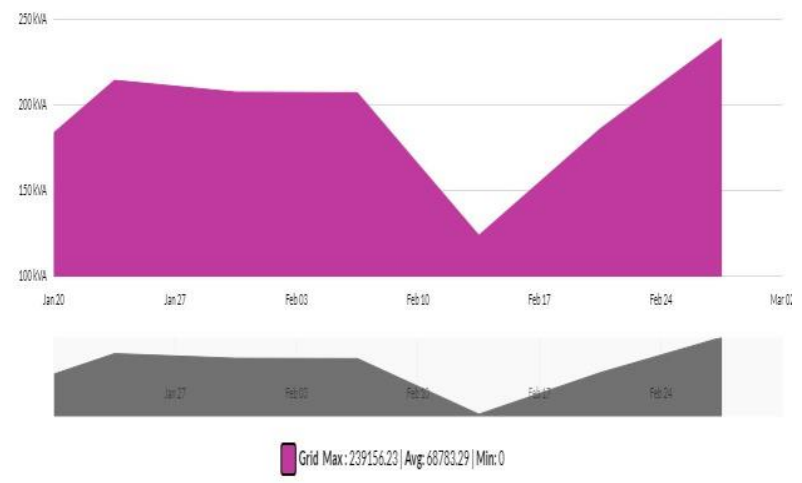

Fig. 5: Apparent Power in KVA per Day.

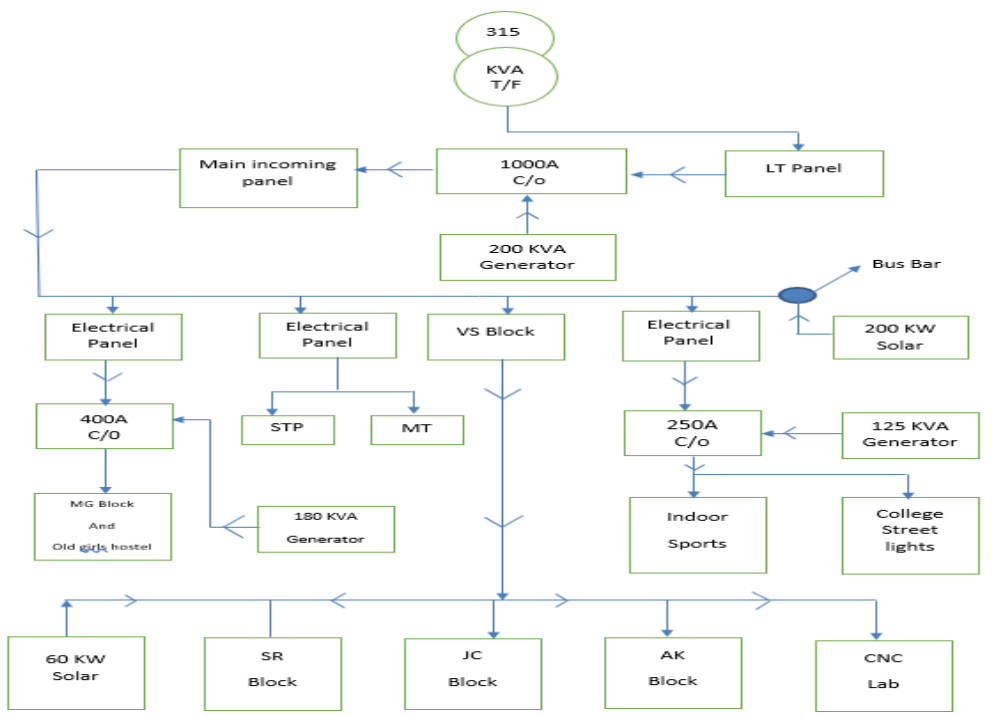

Fig. 6: Single Line Diagram of Distribution of Power in MLR Institute of Technology College Campus.

\section{Methodology for data collection}

Case study and results

DSTs R\&D centre sets an example of solar energy implementation:

MLR institute of technology, an autonomous, R\&D, Centre of Department of Science and Technology (DST), has set up a rooftop solar (RTS) photovoltaic plant of 260-kilowatt' (KWP) capacity. The move is expected to promote best practices of clean energy implementation in scientific institutions. The total plant capacity of 260 KWP has been connected to power grid provided by Telangana State Southern Power Distribution Company Limited (TSSPDCL). Established across two shadow-free building rooftops, it covers an approximate area of 5000 Sq.m with $260 \mathrm{KWP}$ of polycrystalline silicon solar panels. When connected to the grid, only the load that exceeds the plant capacity will be drawn from the Electricity Board, thus reducing the energy consumption.

The annual energy generation of the solar plant is estimated to be 3,79,600 units, and the surplus will be to a tune of $10 \%$, which can be returned back to TSSPDCL as per the mutual agreement. The cost of the project is Rs 1.5 crore, and the plant is in operation since 2018 . By harnessing renewable energy sources, MLR institute of technology, an autonomous R\&D Centre of Department of Science and Technology (DST) has not only aimed at reduction of expenditure on energy but also joined the National Action Plan on Climate Change.

NOTE:

Things yet to be implemented

Power produced by the solar plant can be synchronized with the diesel generators available in the college, which will minimize the diesel consumption.

Table 1: Units Consumption of Various Blocks in the College

\begin{tabular}{lll}
\hline S. NO & Name Of The Block & Units Consumed \\
\hline 1 & AK BLOCK & 151.9 \\
2 & BOYS HOSTEL & 325.7 \\
3 & GIRLS HOSTEL & 204.3 \\
4 & INDOORSPORTS & 363.7 \\
5 & MG BLOCK A & 260.5 \\
6 & MG BLOCK B & 26.9 \\
7 & JC BLOCK & 91.4 \\
8 & MACHINES LAB & 8.9 \\
\hline
\end{tabular}

Table 2: Total Number of Solar Units Generated In Period of 1 Year 


\begin{tabular}{lll}
\hline SI. NO. & MONTH AND YEAR & NO. OF SOLAR UNITS GENERATED \\
\hline 1. & NOV-2018 & 32416 \\
2. & DEC-2018 & 24867 \\
3. & JAN-2019 & 32594 \\
4. & FEB-2019 & 32597 \\
5. & MAR-2019 & 29520 \\
6. & APRIL-2019 & 33324 \\
7. & MAY-2019 & 35097 \\
8. & JUNE-2019 & 34771 \\
9. & JULY-2019 & 25758 \\
10. & AUG-2019 & 32862 \\
11. & SEP-2019 & 22957 \\
12. & OCT-2019 & 24729 \\
13. & NOV-2019 & 32191 \\
14. & DEC-2019 & 24193 \\
15. & JAN-2020 & 28599 \\
\hline
\end{tabular}

Total Electrical Energy (kWh) 74,804

\section{Electric meters-real time readings}

16-Jan 2020 to 02-March 2020

- Marri Laxman Reddy Institute Of Technology

Peak Demand $(\mathrm{kW}) \quad=\quad \mathbf{1 6 9 . 6 6}$

Average Load Factor $\quad=\quad \mathbf{0 . 2 6}$

Solar Generation $(\mathrm{kWh})=\mathbf{1 7 , 2 2 8}$

Peak Demand $(\mathrm{kW}) \quad=\quad \mathbf{1 9 4 . 5 9}$

Load Factor $\quad=\quad \mathbf{0 . 2 8}$

Energy Usage Intensity in $(\mathrm{kWh} / \mathrm{m} 2)$.

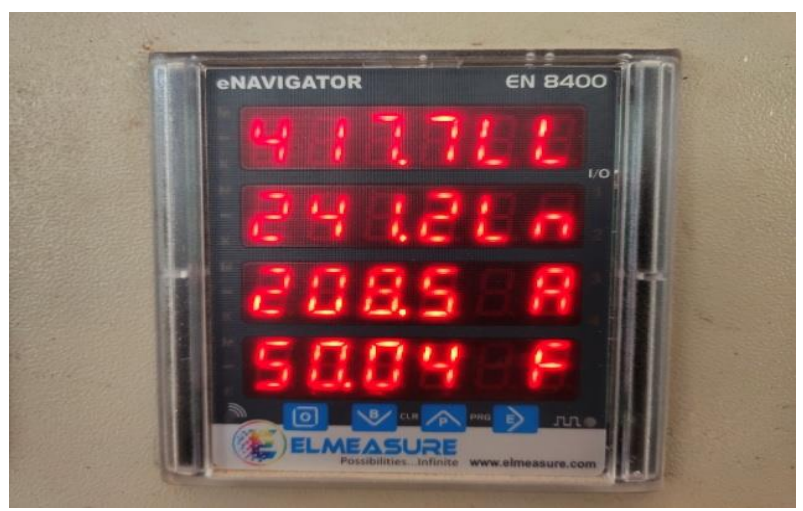

Fig. 5: Digital Energy Meter Readings.

\section{Conclusions \& future scope}

By using IOT based campus energy monitoring and controlling system using Raspberry Pi, entire college having different loads like street lights, Underground motors, Hostel buildings loads, kitchen equipment's and college individual blocks like classrooms, laboratories and all electrical loads can be operated, monitored and controlled using internet of things. By using Internet of things (IOT) we can operate the college street lights, ON \& OFF in time, so that units consumption will be saved. If IOT based underground motors will be operated in time, then the maximum amount of energy in KWH can be saved. peak loads and base loads can also be monitored and operated using IOT. Kitchens, hostel buildings can also be controlled using IOT. All the classrooms and laboratory electrical equipment can be controlled by using IOT.

\section{References}

[1] A. Chersin, W. Ongsakul, and J. Mitra, "Improving of uncertain power generation of roof top solar pv using storage," in Green Energy for Sustainable Development (ICUE), 2014 International Conference and Utility Exhibition on, March 2014, pp. 1-4.

[2] H. Delavaripour, H. R. Karshenas, A. Bakhshai, and P. Jain, "Optimum battery size selection in standalone renewable energy systems," in Telecommunications Energy Conference (INTELEC).

[3] Y. Kumar and R. Bhimasingu, "Optimal sizing of microgrid for an urban community building in south india using homer," in Power Electronics, Drives and Energy Systems (PEDES).

[4] Z. Ren, G. Grozev, and A. Higgins, "Modelling impact of pv battery systems on energy consumption and bill savings of australian houses under alternative tariff structures," Renewable Energy.

[5] Y. P. Kumar and R. Bhimasingu, "Renewable energy based microgrid system sizing and energy management for green buildings," Journal of Modern Power Systems and Clean Energy.

[6] J. Venkatesh, S. Chen, P. Tinnakornsrisuphap, and T. S. Rosing, "Lifetime-dependent battery usage optimization for grid-connected residential systems," in Modeling and Simulation of Cyber-Physical Energy Systems. 
[7] Hanna Talei, D. Benhaddou, Mohamed Essaaidi "Smart campus energy management system advantages architectures and the impact of using IOT".

[8] Introduction, "Energy Management Systems in Microgrid Operations.pdf," Electr. J., vol. 25, no. 8, 2012.

[9] B.Raja sekhar and N. M. Pindoriya, "Multi-stage scheduling for a smart home with solar pv and battery energy storage??? a case study," in Smart Grid Technologies-Asia (ISGT ASIA), 2015 IEEE Innovative. IEEE, 2015, pp. 1-6.

[10] Z. Ren, G. Grozev, and A. Higgins, "Modelling impact of pv battery systems on energy consumption and bill savings of australian houses under alternative tariff structures," Renewable Energy, vol. 89, pp. 317-330, 2016. 